\title{
Desigualdade e juventude: reflexões acerca de critérios adotados pelo plano nacional de assistência estudantil no Brasil
}

\author{
Mariana Oliveira, Swamy Soares, Ruy de Deus \\ e Mello Neto
}

\section{Resumo}

Criado pela Portaria Normativa do Ministério da Educação n 39, de 12 de dezembro de 2007, o Plano Nacional de Assistência Estudantil (PNAES) surge no contexto de expansão e democratização da educação superior no Brasil. O público atendido pelo plano deve ser composto por discentes regularmente matriculados em cursos de graduação presencial, oriundos da rede pública da educação básica ou com renda familiar per capita de até um salário mínimo e meio. Esses critérios tendem a classificar como iguais os jovens que, embora delimitados por um recorte de renda comum, possivelmente sejam originários das mais diferentes matrizes familiares e, mais importante, pertencentes a substratos socioeconômicos diferenciados no interior do recorte adotado. Baseado nas contradições acima apresentadas, o esforço do presente artigo concentra-se em refletir sobre como o plano emerge no contexto da expansão do ensino superior, discutindo possíveis discrepâncias em decorrência de uma concepção de público alvo sem uma maior preocupação com suas diferenças internas. Para tanto, por meio da discussão conceitual e da análise de dados do Exame Nacional de Desempenho nos anos de 2015 a 2017, procura-se demonstrar não haver um padrão entre os alunos do Sistema Federal de Ensino Superior enquadrados no perfil adotado pelo plano.

Palavras-chave:

juventudes e pobreza; expansão do ensino superior no Brasil; assistência estudantil. 


\title{
Inequality and youth: reflections about the criteria adopted by the National Student Assistance Plan in Brazil
}

\begin{abstract}
The National Student Assistance Plan - PNAES - emerges in the context of expansion and democratization of higher education in Brazil. It was created by the Ordinance of the Ministry of Education No. 39, from December 12, 2007. The target audience for This plan is students regularly enrolled in undergraduate courses, coming from public education system, and with per capita family income of less or equal to 1.5 minimum wages. These criteria tend to classify as equal young people who come from the most different family matrices. Notably, people from different socioeconomic backgrounds. Thus, based on the contradictions presented above, the effort of this article focuses on reflecting on how the plan emerges in the context of expansion of higher education, discussing possible discrepancies as a result of a target audience design without greater concern for its internal differences. To this end, through both conceptual discussion and data analysis of the National Performance Exam in the years 2015 to 2017 , we seek to demonstrate that there is no equality between students of the Federal Higher Education System within the profile adopted by the plan.
\end{abstract}

Keywords: youth and poverty; brazilian higher education expansion; student assistance

\section{Desigualdad y juventud: reflexiones sobre criterios adoptados por el Plan Nacional de Asistencia Estudiantil en Brasil}

Resumen: El Plan Nacional de Asistencia al Estudiante (PNAES) surge en el contexto de la expansión y democratización de la educación superior en Brasil. Fue creado por la Ordenanza del Ministerio de Educación No. 39 de 12 de diciembre de 2007. El plan tiene como objetivo ayudar a los estudiantes inscritos regularmente en cursos de pregrado, provenientes del sistema de educación pública, y con un ingreso familiar per cápita de 1.5 salarios. mínimos Estos criterios tienden a clasificar como iguales a las personas que provienen de las matrices familiares más diferentes. Más importante aún, personas de diferentes orígenes socioeconómicos. Por lo tanto, con base en las contradicciones presentadas anteriormente, el esfuerzo de este artículo se enfoca en reflexionar sobre cómo emerge el plan en el contexto de la expansión de la educación superior, discutiendo posibles discrepancias como resultado del diseño de una audiencia sin mayor preocupación por sus diferencias internas. Con este fin, a través de la discusión conceptual y el análisis de datos del Examen Nacional de Desempeño en los años 2015 a 2017, buscamos demostrar que no hay igualdad entre los estudiantes del Sistema Federal de Educación Superior dentro del perfil adoptado por el plan.

Palabras-clave: juventud y pobreza; expansión de la educación superior en Brasil; asistencia estudiantil.

\section{Inégalité et jeunesse: réflexions sur les critères adoptés par le Plan National D'assistance aux Etudiants au Brésil}

Resume: Créé par l'ordonnance normative du Ministère de l'Education n`39 du 12 décembre 2007, le Plan National d'Aide aux Etudiants (PNAES) apparaît dans le contexte de l'expansion et de la démocratisation de l'enseignement supérieur au Brésil. Le public cible du plan devrait être composé d'étudiants régulièrement inscrits à des cours de premier cycle en présentiel, provenant du réseau public d'éducation de base, ou disposant d'un revenu familial par habitant égal au maximum à un salaire minimum et demi. Ces critères tendent à être classés comme des jeunes égaux qui, bien que délimités par un enregistrement de revenu commun, peuvent provenir des types les plus différents de familles et, surtout, appartiennent à des substrats socio-économiques distincts dans les critères adoptés. Ainsi, sur la base des contradictions présentées ci-dessus, le présent article s'efforce de réfléchir à la manière dont le plan émerge dans le contexte du développement de l'enseignement supérieur, en discutant des divergences possibles dues à une conception du public cible sans se préoccuper de leurs différences internes. $\grave{A}$ travers une discussion conceptuelle et de l'analyse des données de l'Examen National de Performance (des années 2015 à 2017), nous essayons de démontrer qu'il n'existe aucune similitude parmi les étudiants du Système Fédéral d’Enseignement Supérieur en ce qui concerne le profil adopté par le plan.

Mots-clés: jeunesses et pauvreté; expansion de l'enseignement supérieur au Brésil; assistance aux étudiants. 


\section{Introdução}

A educação superior no Brasil sofreu significativa transformação no seu perfil discente, caminhando para passar de um sistema de elites para um sistema de massas (Gomes \& Moraes, 2012). Ao longo das últimas duas décadas, evidenciam-se debates que privilegiam as transformações que esse sistema educacional vem sofrendo, em especial àqueles que dizem respeito ao alcance de matrículas, possibilidades de permanência e perfil dos ingressantes. O movimento de expansão, com grande força no sistema público federal em função da atuação dos Institutos Federais de educação superior e, também importante, com o advento do Programa de Apoio a Planos de Reestruturação e Expansão das Universidades Federais - REUNI (Decreto 6.096, de 24 de abril de 2007), termina por pressionar o Governo Federal a responder demandas ligadas à assistência estudantil.

Além de uma mudança significativa no desenho da educação superior federal em termos de acesso com forte impacto das Leis de Cotas (Brasil, 2012) e dos sistemas unificados de seleção (Novo Enem e Sisu), o perfil dos ingressantes também acompanhou uma série de transformações ocorridas na sociedade brasileira. Mais especificamente, a melhoria de indicadores sociais e de distribuição de renda na primeira década do século XXI, a entrada de estudantes negros e pardos (seja em decorrência do crescimento econômico de regiões que concentram boa parte dessa população no país, seja por via de legislações que apontaram para as cotas sociais/raciais), os mecanismos de ingresso à universidade que garantiam maior mobilidade no território a partir da unificação dos processos de seleção, dentre outros fatores, contribuíram para uma mudança também nas demandas em relação à assistência estudantil.

Criado pela Portaria Normativa do Ministério da Educação n 39, de 12 de dezembro de 2007, o Plano Nacional de Assistência Estudantil (PNAES) surge no contexto de expansão e democratização da educação superior, segundo as diretrizes apontadas pelo governo do Presidente Luiz Inácio Lula da Silva. O marco legal atual da política de assistência estudantil está regulamentado no Decreto n 7.234/2010, que apresenta, em sua redação inicial (Art. $2^{\circ}$ ), seus objetivos:

I-Democratizar as condições de permanência dos jovens na educação superior pública federal; II - minimizar os efeitos das desigualdades sociais e regionais na permanência e conclusão da educação superior; III - reduzir as taxas de retenção e evasão; e; IV - contribuir para a promoção da inclusão social pela educação.

Esses objetivos exigem das instituições o desenvolvimento das ações previstas de modo a identificar as demandas de seu público-alvo, tendo em vista a mudança de perfil dos estudantes da educação superior das últimas décadas. O decreto avança também na atenção aos estudantes com deficiência, transtornos globais do 
desenvolvimento e altas habilidades e superdotação, tidos como incapazes de serem incluídos no processo formativo, inseridos no centro do debate das ações a serem desenvolvidas enquanto estratégias que gerem acesso, participação e aprendizagem de um público mais específico.

O público atendido pelo PNAES deve ser constituído discentes regularmente matriculados em cursos de graduação presencial, oriundos da rede pública de educação ou com renda familiar per capita de até um salário mínimo e meio nacional (Brasil, 2010). Além destes critérios, as Instituições Federais de Educação Superior (IFES) podem fixar outros requisitos através de regulamentação própria a ser formulada no âmbito de cada instituição.

Por outro lado, se é verdade que se delega às instituições a definição de regras específicas para cada local, há também na documentação que regulamenta o plano uma concepção de recorte de renda que serve como guia básico de elegibilidade ao financiamento. De tal modo, o PNAES, ao mesmo tempo em que consegue oportunizar o ensino superior a jovens que são, provavelmente, diferenciados em relação a grande parte de seus colegas, mostrando-se uma importante via de manutenção destes estudantes na Rede Federal de Ensino Superior, no critério majoritário há, em si, uma inevitável arbitrariedade; de tal maneira, são classificados como iguais jovens que, embora delimitados por um recorde de renda comum, possivelmente sejam originários das mais diferentes matrizes familiares e, mais importante, pertencentes a substratos socioeconômicos dispares no interior do recorte adotado.

Por meio de uma elegibilidade baseada em renda e tipo de instituição de ensino médio, o plano define seu público-alvo sem considerar possíveis diferenças existentes ocorridas entre distintos estudantes no bojo de sua seleção - delegando às instituições o controle de possíveis discrepâncias sem, contudo, traçar regulamentações mais objetivas para tanto. Na prática, cabe às IFES escolher os possíveis contemplados dentre àqueles aptos pela regulamentação oficial.

É importante lembrar que a maioria absoluta dos jovens inscritos no Enem (Mello Neto, 2015) seria enquadrada na faixa de renda adotada pelo PNAES. Ou seja, mesmo com o advento das Políticas de Cotas Federais - que adota, em partes, o mesmo critério -, ainda há, no bojo do candidatáveis ao PNAES, uma possível diversidade grande de perfis e trajetórias.

De tal maneira, baseado nas contradições acima apresentadas, nosso esforço, no presente artigo, concentra-se em refletir sobre como o PNAES emerge no contexto da expansão do ensino superior, discutindo possíveis discrepâncias em decorrência de uma concepção de público-alvo sem uma maior preocupação com diferenças internas ao recorte adotado. 


\section{Posicionando os autores: perspectivas de juventudes}

Temos ciência de que o PNAES não é, em si, uma política exclusivamente voltada às juventudes, já que não há uma delimitação de público-alvo pautado em idade. Ainda assim, entendemos que se faz importante posicionar-nos nesse sentido, uma vez que o debate aqui proposto tem como norte analítico uma limitação das políticas de expansão do ensino superior no Brasil e estas preconizavam a inclusão de jovens no ensino superior.

Mais especificamente, a necessidade de ampliar o número de estudantes no ensino superior brasileiro vem sendo tratada como requerimento básico ao desenvolvimento nacional por longos anos, ficando clara desde o Plano Nacional de Educação (PNE 2001-2010) (Brasil, 2001), em que se preconizava a necessidade de expansão do número de vagas ocupadas no ensino superior para jovens entre 18 e 24 anos, especialmente para jovens de baixa renda e com históricos familiares de desvantagem social.

No tocante às políticas públicas e programas voltados para as juventudes, encontramos diversos trabalhos que problematizam o modo como as juventudes são tematizadas em momentos distintos na história da América Latina (Abad, 2008; Bango, 2008; Sposito, 2003 etc.). Não há, deste modo, uma maneira única de compreensão das do que significa ser jovem e das suas necessidades. As agendas públicas abordam este grupo populacional de diferentes formas, resultado das necessidades de cada sociedade e das disputas nelas forjadas.

Deixamos aqui claro que nos localizamos junto aos pesquisadores que concebem os jovens como "sujeitos sociais de direitos" (Dayrell, 2003; Carrano \& Sposito, 2003), não apenas alvo das políticas educacionais, mas como protagonistas no cotidiano da vida pública, inclusive na elaboração dos programas governamentais. Essa decisão, que não é apenas teórica, reflete-se na nossa prática enquanto educadores e gestores e tem sua importância na demarcação de como temos nos relacionado com os jovens estudantes das universidades públicas. Esse posicionamento também deve (nos) provocar e auxiliar nas avaliações e análises das políticas de permanência e assistência estudantil da educação superior.

Além disso, fazendo uma alusão referente ao lugar e objetivos das universidades públicas no contexto da globalização, Sobrinho (2005) nos alerta a respeito do devido cuidado que devemos tomar com as dimensões ética e política constituintes do caráter público das instituições de educação superior. Segundo o autor,

A educação superior é um patrimônio público na medida em que exerce funções de caráter político e ético, muito mais que uma simples função instrumental 
de capacitação técnica e treinamento de profissionais para as empresas. Essa função pública é a sua responsabilidade social. É sumamente importante que a educação superior produza conhecimentos e formação com um grande sentido de pertinência social. [...]. Por meio do conhecimento e do trabalho de formação, sem abdicar de suas competências críticas, ela deve desenvolver a capacidade de resposta às demandas e às carências da sociedade. (Sobrinho, 2005: 171).

As provocações do autor vão nos encaminhando para destacar qual a concepção de educação assumida por nós neste artigo. Apostamos um conceito de educação que extrapola a ideia de escolarização e/ou daquela que apenas se compromete com a preparação para o mercado de trabalho. Dessa forma, sem considerar esses dois importantes aspectos, concebemos a educação enquanto processos formativos que admitem a escolarização, formação para o mundo do trabalho (não apenas para o mercado) e que contemplem elementos de uma formação humana e política para a vida em sociedade. Essa concepção dialoga com a ideia de Hanna Arendt (1906 1975) sobre uma formação que deve ser comprometida com a vida em coletividade, isso significa uma sensibilização para o reconhecimento dos conflitos e diferenças do (con) viver com o outro. Espera-se, consequentemente, que as políticas educacionais pensadas e desenvolvidas pelas instituições de educação superior, apresentem uma compreensão sobre juventudes e educação que não se limite aquelas ideias restritivas de investir nas juventudes como o "futuro de uma país" (ideia salvacionista) ou como uma anomia que oferece perigo à ordem social e, por isso, precisam sofrer ações interventivas.

Nos interessa fazer um recuo e provocar cavidades que permitam reconhecer o [não] lugar das juventudes na gestão e na execução de programas voltados para esse público. Ou seja, é intenção nossa compreender como os documentos da política de permanência tem (ou não) abarcado os interesses, desejos e demandas dos jovens, os concebendo como sujeitos políticos e não como problema a ser sanado. Esses elementos devem contribuir para a garantia de ações menos excludentes na vida universitária. Nesse sentido, reconhecer as limitações das regras que colocam sujeitos de diferentes matrizes histórico-familiares dispares como equivalentes é, sobretudo, dar voz aos subgrupos dos excluídos dentre os assim reconhecidos pelo Estado brasileiro. Faz-se importante reconhecer que há uma enormidade de perfis e de realidades socioeconômicas, impossibilitando uma classificação mais geral de juventude a ser contemplada por ações governamentais, caso tal classificação seja operada unicamente por critérios de renda e tipo de instituição no ensino médio. Há, deste modo, uma realidade pautada em uma enorme diversificação do perfil de jovem no bojo dos candidatáveis ao PNAES, na qual sujeitos desiguais disputam espaços sendo tratados como iguais. 


\section{Juventude, Inclusão e as Instituições de Ensino Superior}

Em um contexto histórico, os jovens foram alvo de ações governamentais como aqueles que deviam ser integrados socialmente, principalmente no período de redemocratização e modernização dos países da América Latina. Outra orientação mais presente a partir dos anos 1980 tem como foco a erradicação da pobreza e contenção de comportamentos considerados delinquentes e, mais recentemente, notamos uma luta para que sejam tematizados como sujeitos de direitos. Nas diversas orientações e maneiras de abordagem das políticas, os jovens para quem são endereçadas as ações governamentais consistem naqueles considerados em situação de pobreza. Uma outra predominância é a expectativa de inseri-los no mercado de trabalho e um grande investimento em ações educativas.

A reflexão sobre os desafios vivenciados pelas instituições de ensino no que tange às culturas juvenis não se trata de uma questão recente (Silva et al., 2016; Carrano, 2011). As relações entre professores e estudantes, permeadas pelas multiplicidades de realidades sociais, econômicas, culturais, reforçam a dinâmica nada simplória do (com)viver no contexto da vida universitária. Os conflitos geracionais, as linguagens, interesses e o fazer/viver a universidade, muitas vezes são conflituosos entre os sujeitos que a compõem.

Além da diversidade de existências, os jovens estudantes não escapam do funcionamento de uma cultura institucional que reproduz e reforça normativas homogeneizantes, conformadoras e excludentes próprias das instituições sociais e dos processos escolarizantes tradicionais. A universidade é, ao mesmo tempo, lugar de aposta na construção de novos saberes e de "portas que se abrem" para o mundo do trabalho e espaço de conflito de interesses e desejos dos jovens. Ou seja, nem sempre os estudantes atribuem sentidos materiais e humanos à sua presença na instituição como um todo e nos cursos de maneira mais específica.

Apesar da cultura escolar estar bastante presente na universidade, não podemos deixar de reconhecer que existe um modus operandi próprio das instituições de educação superior. Ele se materializa, por exemplo, na exigência de maior autonomia dos estudantes sobre seus processos formativos, oferece oportunidades, mesmo que de maneira desigual, a participarem de projetos de pesquisa e extensão, além de espaços de convivência social e acadêmica nada semelhantes a escola de educação básica.

Um aspecto de bastante relevância que nos ampara nas reflexões sobre juventudes e educação é considerar o funcionamento da universidade no que diz respeito aos objetivos formativos. Nesse sentido, não podemos deixar de compreendê-la no contexto de interesses sociais e econômicos presentes na sociedade, já que se configura como uma instituição social, o que, naturalmente, impacta todo o jogo de poderes internos, fazendo com que regras e definições sigam uma lógica quase sempre econômica e/ 
ou contextualizadas com os valores dominantes de cada instituição. No caso aqui em tela, as regras de definição de público alvo ao PNAES em cada instituição resultam de uma disputa pelo domínio das regras do jogo, ao mesmo tempo em que passam pela percepção dos atores das IFES sobre juventudes excluída - o que, convenhamos, salvo casos específicos em que estudos mais rigorosos são feitos, costumam ser precedidas de um alto grau de arbitrariedade. E é justamente nos limites de tal arbitrariedade que se centra esse artigo. O argumento central aqui apresentado é que o recorte geral adotado é incompetente em definir um perfil de estudante comum, sendo evidenciada uma grande disparidade de perfis no escopo definido pelo recorte de renda e tipo de instituição de ensino médio.

\section{PNAES e o recorte de classe adotado}

Partindo do pressuposto de que todo plano de ação está norteado por referenciais que trazem subjacentes compreensões específicas a respeito do problema social existente e sobre as orientações e meios destinados a solucioná-lo (Azevedo, 2003), e que esses referenciais, por sua vez, também são resultantes de uma construção histórica que se relaciona com os valores dominantes de um determinado período ou conjuntura, um primeiro movimento a ser observado é de que o plano procura abranger, em termos de concepção, uma discussão ampla das demandas e, porque não afirmar, das possibilidades dos jovens oriundos do mesmo.

Vale ressaltar que a política pública não pode ser compreendida como um todo homogêneo, mas como algo complexo que envolve conceitos tanto na sua formulação quanto na sua implementação. Esses conceitos são, por um lado, parcialmente estáveis no momento em que a ação (plano ou projeto) expressa necessariamente o resultado de embates políticos e sociais anteriores. Por outro lado, mesmo uma política constituída (portanto, com objetivos e metas delimitados) contém um elemento instável, ligado à ação dos atores sociais que se envolvem com ela (a política) e a (re) significam nos movimentos de implementação.

A constatação desse movimento baseia-se na ampliação de atuação do PNAES, apontando para uma visão de público para além da delimitação econômica (de classe). Não estamos querendo, em nenhum momento, diminuir a classe como elemento importante (senão, central) do plano, muito menos sua relevância teórica para compreensão dos fenômenos juvenis no contexto de uma sociedade capitalista. Contudo, compreendemos que as concepções de classe devem dialogar com outros elementos que "compõem" as juventudes, tanto em termos de demandas, quanto no reconhecimento destas pessoas como sujeitos de direito. Nesse panorama, o próprio termo pobreza esconderia uma série de elementos heterogêneos pretensamente ocultados na generalização do conceito. Ainda que o elemento socioeconômico seja importante 
para definir ações e interpretações sobre as classes populares, ele por si não explicaria as inúmeras vivências e possibilidades de viver a condição de vida dessas pessoas.

Seria importante, nos dizeres de Margulis (1998), perceber as diferenças de gênero, raça/etnia, experiências geracionais, com o lugar e com os distintos processos de integração ao mundo do trabalho e escolarização. O desafio seria o de compreender os grupos sociais sem reduzi-los a uma categoria preestabelecida, seja ela socioeconômica ou sociocultural (Dubar, 2005). Sendo assim, afirmamos que nossas análises expressam a "limitação" de perceber esse primeiro movimento, ou seja, as concepções "estáveis" que a política apresenta.

Para tanto, parte-se da premissa que características histórico-familiares e socioeconômicas impactam a vivência no ensino superior como um todo, sendo uma delimitação exclusivamente feita por recorte de renda e tipo de instituição de ensino médio inadequada à definição de um perfil de público-alvo homogêneo. Assume-se aqui que, embora pertencentes a um mesmo corte de renda, a depender de condicionantes socioeconômicos, trata-se de situações de vivência no ensino superior diametralmente distintas.

\section{A diversidade e o perfil do estudante habilitado ao PNAES}

Em busca de mapear o perfil dos estudantes matriculados nas IFES e habilitados ao PNAES, observou-se os dados referentes aos questionários socioeconômicos dos exercícios de 2015, 2016 e 2017 do Exame Nacional de Desempenho dos Estudantes (Enade) $^{1}$ (Brasil, 2004) (INEP, 2019a; 2019b; 2019c). Tal decisão deve-se ao fato que o ciclo de cursos do exame é trienal; assim pôde-se obter uma amostra representativa e probabilística de todas as graduações e estudantes possíveis.

Foram excluídos da amostra os estudantes que: (1) não fossem matriculados em instituições públicas federais²; (2) estudantes que não participação comprovada no exame; ; (3) estudantes matriculados em cursos à distância ${ }^{4}$; e (4) estudantes com respostas ausentes em alguma das variáveis observadas.

Trata-se de amostra expressiva, apresentando distribuição em todo território nacional, além de contar com todos os cursos ofertados em IFES. Além disso, conta com a metodologia de distribuição adaptada pelo Instituto Nacional de Estudos e Pesquisas Educacionais "Anísio Teixeira" (Inep), a qual é considerada equânime entre cursos e regiões, posto ser obrigatório ${ }^{5}$ ao estudante graduando a realização do exame.

Para cálculo da renda familiar dos estudantes foi considerada a média do intervalo para a variável sobre renda (var = QE_I08). Ou seja, rendas familiares entre a e $b$ foram tidas como rendas iguais $(a+b)$ /2. Para a opção "acima de 30 salários mínimos" de renda familiar, foi adotado o valor de 30. Para cálculo da renda per capita familiar, foi dividido o resultado obtido na variável anterior pelo número de pessoas residentes na 
mesma casa de que o estudante (var = QE_I08). Nos casos em que a variável apresentou a resposta "7 ou mais", foi considerado arbitrariamente como 8.

Posteriormente, de modo a restringir a amostra aos estudantes habilitados a participar do PNAES, foram excluídos estudantes que tenham renda per capita familiar acima de 1,5 salários mínimo e àqueles que não tenham concluído o ensino médio todo em escolas da rede pública ${ }^{6}$. Ao fim, um total de 68.997 questionários socioeconômicos foram analisados.

Voltando ao mapeamento dos estudantes, o critério seletivo do plano não define o perfil esperado dele. Entretanto, aponta condições objetivas de candidatura, podendo, então, vir a funcionar como ferramenta de diferenciação entre habilitados e inabilitados. De todo modo, tendo como norte fatores histórico-familiares e socioeconômicos, além da renda familiar per capita, observou-se a distribuição dos estudantes de acordo com: (1) Raça; (2) Renda; (3) Gênero; (4) nível de formação dos pais; (5) histórico familiar de acesso ao ensino superior; (6) curso; e (7) região.

Decidiu-se também pelo agrupamento destes em função dos quartis de renda familiar per capita da amostra. Os estudantes serão apresentados como pertencentes a uma das 4 faixas, subdivididas pele seguinte recorte: (1) primeira faixa de renda - sujeitos com que tenham renda familiar per capita entre 0 e 0,3214 salários mínimos; (2) segunda faixa de renda - sujeitos com renda familiar per capita entre 0,3215 e 0,5625 salários mínimos; (3) terceira faixa de renda - sujeitos com renda familiar per capita entre 0,5626 e 0,8750 salários mínimos; e (4) quarta faixa de renda - sujeitos com renda familiar per capita entre 0.8751 e 1,5 salários mínimos.

Além de gráficos com percentuais, serão exibidos resultados em formato box-plot, seguidos de uma tabela descritiva. Para efeito de comparação, os gráficos box-plot contarão com uma linha referencial (em vermelho) delimitando a mediana e com duas linhas laranjas delimitando os dois quartis, ambas da amostra geral.

Por fim, cabe destacar que os dados que serão apresentados ao longo deste texto trazem ao debate a percepção de quem não há um padrão de estudante classificado pela regulamentação do PNAES e que, em função disso, há processos de distinção internas ao plano que colocam sujeitos com histórico familiar e social desiguais sendo compreendidos como iguais.

\section{Educação Familiar}

Após agrupamento dos estudantes, propõe-se aqui a observação de possíveis diferenças no histórico familiar e na relação entre estudantes de diferentes agrupamentos. Em tal sentido, observa-se uma grande disparidade entre o perfil de formação dos pais quando comparados sujeitos pertencentes a cada uma das 4 faixas de renda. 


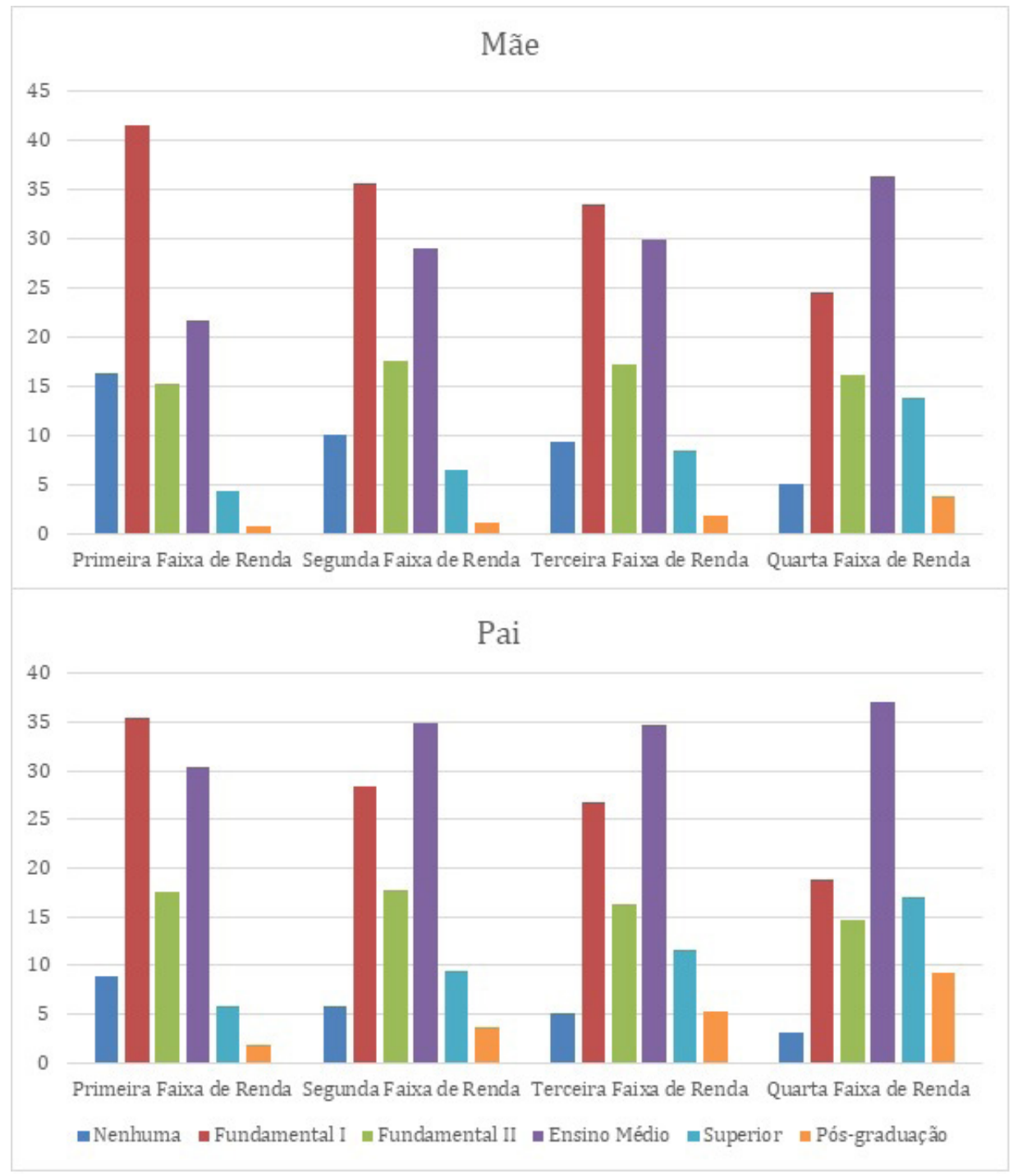

Figura 1: Formação da Mãe e do Pai por Faixa de Renda do Estudante Fonte: Inep (2019a, 2019b, 2019c)

Enquanto os estudantes da quarta faixa de renda concentram 54,2\% das mães e 63,3\% dos pais com, no mínimo, o ensino médio completo, os da primeira faixa de renda possuem $73,1 \%$ das mães e $62,1 \%$ dos pais com, no máximo, o ensino fundamental II completo. 
Quando perguntados sobre a existência de algum familiar que tenha concluído o curso superior, os dados revelam também uma diferença de percentual entre os estudantes de cada uma das faixas de renda - com uma maior probabilidade de histórico familiar de acesso ao ensino superior dos estudantes no quartil superior.

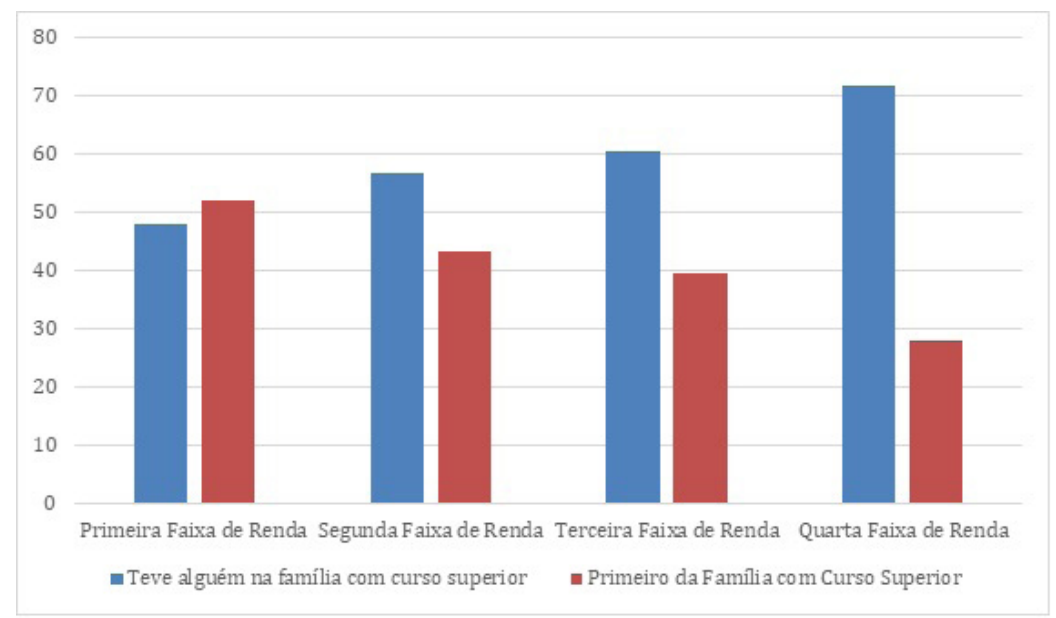

Figura 2: Existência de Algum Familiar que Tenha Concluído o Curso Superior por Quartil de Renda do Estudante. Fonte: Inep (2019a, 2019b, 2019c)

Enquanto a maior parte $(52,1 \%)$ dos estudantes da primeira faixa de renda se apresentem como o primeiro da sua família a concluir o ensino superior, no caso dos jovens da faixa mais alta de renda, aproximadamente $72 \%$ deles possuem algum familiar que concluiu o ensino superior.

\section{Raça e Renda}

Não obstante a diferença no histórico familiar de acesso ao ensino superior, os resultados apontam que, embora a maior parte dos estudantes habilitados ao PNAES declare-se do gênero feminino, são os autodeclarados masculinos que se posicionam na parte mais alta dos agrupamentos de renda.

A exceção dos amarelos, os homens apresentam recortes de mediana e de quartis maiores ou iguais ao seu equivalente de declaração feminino. Além disso, faz-se claro que os pretos, pardos e indígenas (PPI) apresentam um perfil distinto de renda em relação aos brancos e amarelos. Ou seja, mesmo tendo um teto de renda estabelecido, a estratificação racial se mantém. Os PPI exibem as três unidades observadas (quartis e mediana) abaixo do apresentado pela amostra geral, tendendo a fazer parte de uma faixa de renda mais baixa que os colegas habilitados ao PNAES. 


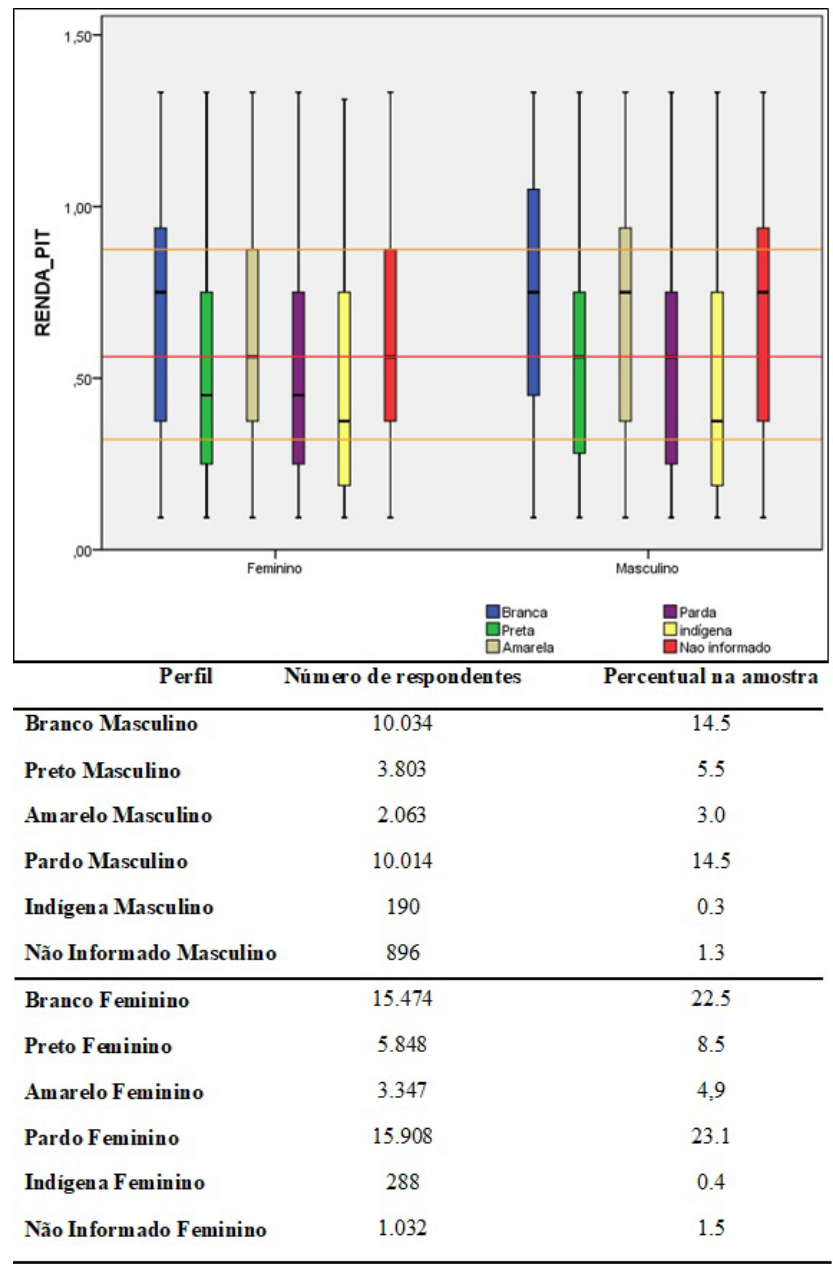

Figura 3: Box-Plot da Renda por Raça e por Renda/Tabela Descritiva das Variáveis Fonte: Inep (2019a; 2019b; 2019c)

Tal distinção fica ainda mais evidente quando observamos os quartis de forma isolada. Ao mesmo tempo em que, dentre os brancos, $35.1 \%$ dos homens e $32.1 \%$ das mulheres concentram-se entre os $25 \%$ mais ricos da amostra, no caso dos indígenas, $43,8 \%$ dos homens e $45,6 \%$ das mulheres encontram-se entre os $25 \%$ mais pobres da amostra. A título de comparação, quase metade dos indígenas encontram-se em uma faixa de renda menor do que 0,3214 salários mínimos per capita (quartil inferior da amostra geral), enquanto apenas $14,9 \%$ dos homens brancos e $18 \%$ das mulheres encontram-se na mesma posição. 


\section{Regiões do Brasil}

A distribuição dos estudantes por diferentes regiões do Brasil evidencia uma enorme concentração de estudantes das faixas de renda.

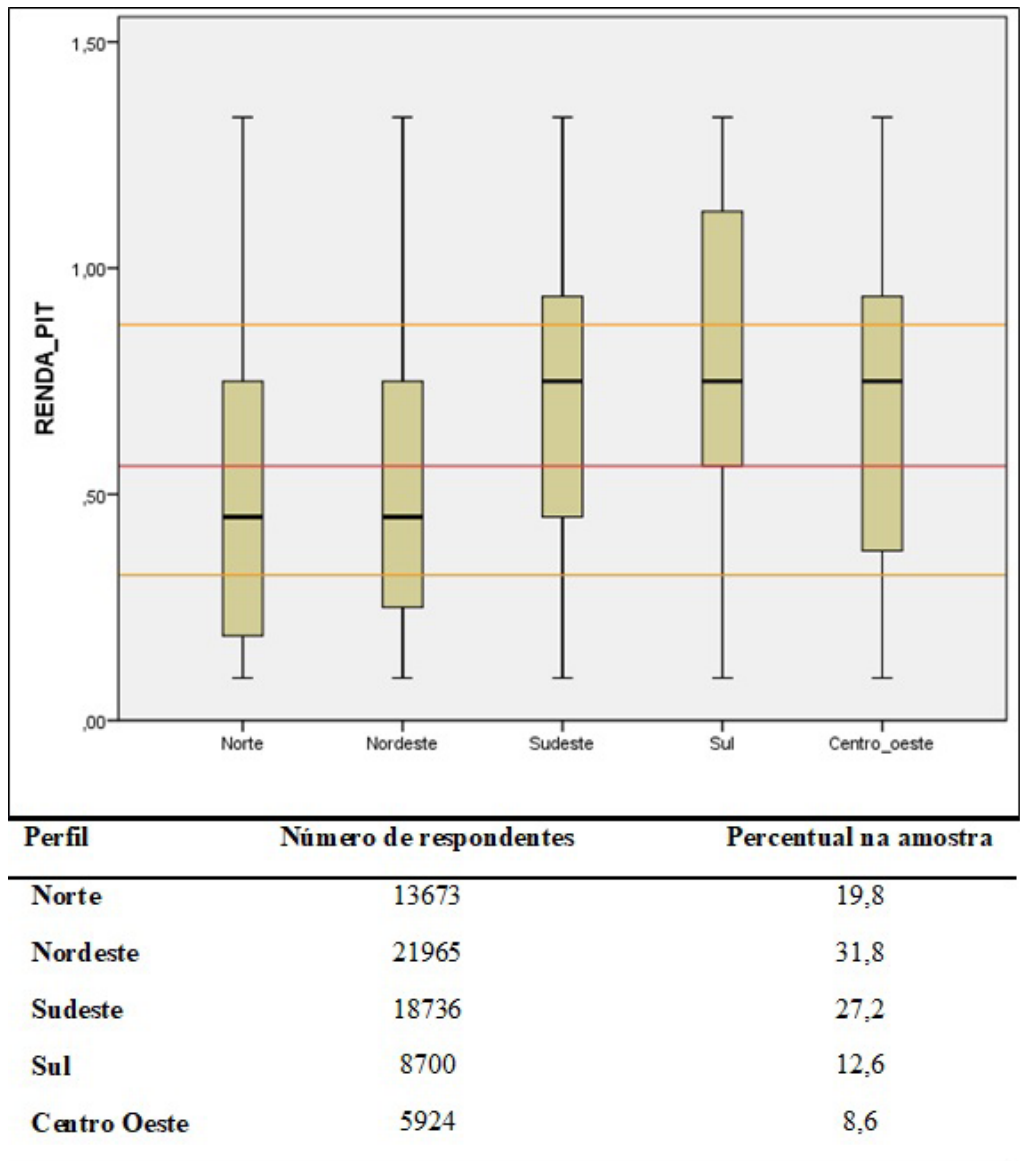

Figura 4: Box-Plot da Renda por Regiões do Brasil /Tabela Descritiva das Variáveis Fonte: Inep (2019a; 2019b; 2019c)

A região nordeste e a região norte concentram grandes percentuais de estudantes nas faixas mais baixas de renda. $65,7 \%$ dos estudantes do norte e $62 \%$ dos do Nordeste encontram-se abaixo da mediana da amostra (nas duas faixas menores de renda), ao tempo que, em sentido oposto, no Sul e no Sudeste, a maior parte dos estudantes concentram-se nas duas faixas mais altas de renda $(60,4 \%$ e $67,5 \%$ respectivamente). 


\section{Curso de graduação}

De forma a observar discrepâncias entre diferentes cursos, agrupou-se os estudantes por área específica, seguindo a tabela da Organização para a Cooperação e Desenvolvimento Econômico (OCDE) ${ }^{7}$.

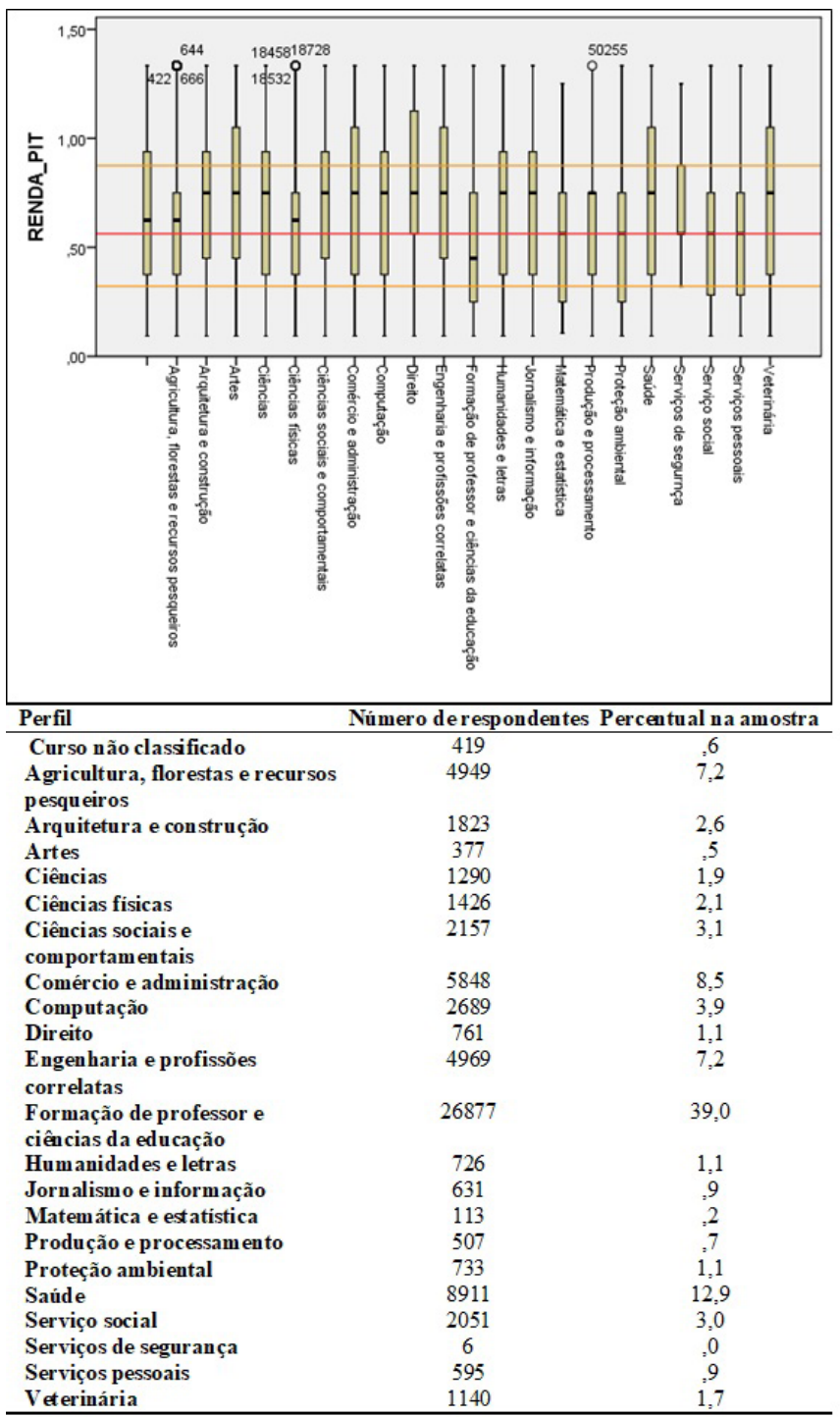

Figura 5: Box-Plot da Renda por Área Especifica /Tabela Descritiva das Variáveis Fonte: Inep (2019a; 2019b; 2019c) 
Mais uma vez chama atenção a discrepância no perfil discente de alguns cursos em relação aos outros. Enquanto, por exemplo, 44,7\% dos alunos de direito encontram-se na quarta faixa de renda. No outro extremo, 31,5\% dos alunos de cursos de Formação de professor e ciências da educação são classificados como pertencentes à primeira faixa de renda.

\section{Discussão e Algumas Considerações}

Os dados apresentados e as considerações conceituais expostas nesse artigo nos levam a dois movimentos. O primeiro, ligado à necessidade de compreensão do perfil dos integrantes do PNAES, tanto no panorama nacional, quanto nas realidades locais. Esse movimento, dinâmico por natureza, considerando o perfil do plano e a rotatividade daquelas e daquelas que compõem o PNAES, nos ajuda a analisar em que medida a política cumpre seus objetivos e como essa dinâmica a reconfigura. Obviamente, para além da caracterização, é necessário o aprimoramento de pesquisas que cruzem os perfis de entrada com a situação de permanência, incluindo aí os rendimentos acadêmicos. Em ações como o PNAES, a trajetória acadêmica não revela apenas a pertinência do plano em relação aos objetivos, mas especialmente a atuação/interferência das IFES no que se refere às ações acadêmicas/pedagógicas. Por isso, a necessidade de compreensão dos dados a partir de estratificação por cursos e áreas

de conhecimento. É necessário compreender o movimento de "recepção" destes jovens pelas instituições de ensino superior; jovens estes, que muitas vezes, "quebram" certos modelos pré-concebidos historicamente do que deve (ou deveria) ser um estudante universitário.

O outro movimento analítico, intercalado com o primeiro, diz respeito às mudanças das ações políticas do plano frente ao perfil de jovens a quem se dirige. Esse, portanto, é o movimento que se insere na dialética de compreensão da política pública como algo dinâmico, passível de transformações não apenas de quem a formula (e percebe a realidade), mas principalmente dos atores sociais que a configura nas práticas institucionais. Insere-se nesse movimento analítico a necessidade de compreender a prática do PNAES levando em consideração as culturas institucionais, o posicionamento dos agentes públicos, as ações políticas formais e não formais do que comumente intitulamos por "movimento estudantil", as micro resistências e reconfigurações presentes na ação das pessoas, muitas vezes pouco observadas a partir de uma análise dos dados estatísticos. O artigo de certa forma propõe, em seu fim, uma série de provocações que se inserem em possíveis campos de pesquisa em diálogo com o panorama apresentado anteriormente. A inteligência já construída sobre o PNAES, somado aos desafios futuros, talvez possa nos ajudar nas pistas de compreensão do plano em 
cenários ainda mais densos e confusos como os que estamos vivendo no momento de conclusão deste texto.

\section{Notas}

O Enade tem foco em estudantes matriculados no último ano de graduação, ou que tenham concluído 80\% das disciplinas do curso, e definidos pelo Inep; 2017: CO_CATEGAD $\neq 1$; 2015 e 2016: CO_CATEGAD $\neq 93$ ou 10002; TP_PRES $\neq$ 555; 2016 e 2017: CO_MODALIDADE $\neq$ 1; 2015 = não havia variável neste sentido; Conforme o art. $5^{\circ}, \S 5^{\circ}$ da Lei $n^{\circ} 10.861$, o Enade constitui-se componente curricular obrigatório, sendo inscrita no histórico escolar do estudante somente a situação regular com relação a esta obrigação. O estudante selecionado que não comparecer ao exame estará em situaçã̃o irregular junto Ministério da Educação QUE_l17 $\neq$ A. Estão sem área 419 alunos matriculados em cursos sem classificação no banco de dados do Inep.

\section{Referências}

Abad, M. (2003). Crítica política das políticas de juventude. Políticas públicas: juventude em pauta. São Paulo: Cortez.

Azevedo, J. M. L. (2003). A educação como política pública. Autores Associados.

Bango, J. (2003). Políticas de juventude na América Latina: identificação de desafios. Políticas públicas: juventude em pauta. São Paulo: Cortez.

Brasil. (2001). Lei no 10.172, de 9 de janeiro de 2001. Aprova o Plano Nacional de Educação e dá outras providências. Diário Oficial da União,

Brasil. (2004). Lei no 10.861, de 14 de abril de 2004. Institui o Sistema Nacional de Avaliação da Educação Superior-SINAES e dá outras providências. Diário Oficial da União, (72).

Brasil. (2007a). Portaria Normativa n 39, de 12 de dezembro de 2007. Institui o Programa Nacional de Assistência Estudantil-PNAES. Diário Oficial da União.

Brasil. (2007b) Decreto n 6.096, de 24 de abril de 2007. Institui o Programa de Apoio a Planos de Reestruturação e Expansão das Universidades Federais-REUNI. Diário Oficial da União.

Brasil. (2010). Decreto n 7.234, de 19 de julho de 2010. Dispõe sobre o Programa Nacional de Assistência Estudantil-PNAES. Diário Oficial da União.

Brasil. (2012). Lei $n^{\circ}$ 12.711, de 29 de agosto de 2012. Dispõe sobre o ingresso nas universidades federais e nas instituições federais de ensino técnico de nível médio e dá outras providências. Diário Oficial da União, 149(169).

Carrano, P. (2011). Jovens, escolas e cidades: desafios à autonomia e à convivência. Revista teias, 12(26), 16-23.

Dayrell, J. (2003). O jovem como sujeito social. Revista Brasileira de Educação, 24, 53-62.

Dias Sobrinho, J. (2005). Educação superior, globalização e democratização: qual universidade? Revista brasileira de educação, 28, 164-173.

Dubar, C. (2005) A socialização: construção das identidades sociais e profissionais. São Paulo: Martins Fontes. 
Freitas, M. V. D., \& Papa, F. D. C. (2003). Políticas públicas: juventude em pauta. Cortez: Friedrich Ebert Stiftung.

Gomes, A. M., \& de Moraes, K. N. (2012). Educação superior no Brasil contemporâneo: transição para um sistema de massa. Educação \& Sociedade, 33 (118), 171-190.

Inep (2019a) Microdados do Exame Nacional de Desempenho dos Estudantes 2015. Brasília: MEC/ INEP.

Inep (2019b) Microdados do Exame Nacional de Desempenho dos Estudantes 2016. Brasília: MEC/ INEP.

Inep (2019c) Microdados do Exame Nacional de Desempenho dos Estudantes 2017. Brasilia: MEC/ INEP.

Margulis, M. (1998). La juventud es más que una palabra: ensayos sobre cultura y juventud. Buenos Aires: Biblos.

Mello Neto, R. D. D. (2015). Não vou me adaptar: um estudo sobre os bolsistas pernambucanos durante os 10 primeiros anos do Programa Universidade Para Todos-ProUni. Tese de doutorado, Universidade de São Paulo.

Silva, A. N. O., Alves, A. C. O., \& Silva, H. D. S. (2016). Afirmações e resistências: cultura escolar e juventude. Locus-Revista de História, 22 (2), 28-35.

Sposito, M. P., \& Carrano, P. C. R. (2003). Juventude e políticas públicas no Brasil. Revista Brasileira Educação.[online], (24), 16-39.

Mariana Lins de Oliveira Doutora em Educação pela Universidade Federal de Pernambuco (UFPE).

Professora da Universidade Federal da Paraíba e do Mestrado Profissional em Políticas, Gestão e Avaliação da Educação

Superior - MPPGAV - da UFPB.

E-mail: mariloliveiras@gmail.com ORCID: https://orcid.org/0000-0003-3577-6426

Swamy de Paula Lima Soares

Doutor em Educação pela Universidade de São Paulo (USP).

Professor adjunto da Universidade Federal da Paraíba, atuando no Programa de Pós-Graduação em Políticas Públicas, Gestão e

Avaliação da Educação Superior.

E-mail: swamysoares@ce.ufpb.br ORCID: https://orcid.org/0000-0001-7489-3698 
Ruy de Deus e Mello Neto

Doutor em educação pela Universidade de São Paulo, com doutorado sanduíche na Harvard Graduate School of Education.

É orientador de doutorado no Programa de Pós-Graduação em Educação Faculdade de Educação da Universidade de São Paulo.

Pós-doutorado na Fundação Joaquim Nabuco;

na Faculdade de Educação da Universidade de São Paulo;

na Harvard Graduate School of Education.

E-mail: ruydedeus@usp.br

ORCID: https://orcid.org/0000-0001-6035-5944

Correspondência:

Mariana Lins de Oliveira

Universidade Federal da Paraíba - Campus I

Cidade Universitária - CEP 58051-900 - João Pessoa-PB-Brasil

Data de submissão: Setembro 2019

Data de avaliação: Dezembro 2019

Data de publicação: Novembro 2020 
